\title{
Espaços Funcionais como Modos de Governança além de Limites Físicos e Político-Administrativos: exemplos no Brasil e na Suíça
}

\author{
Soft Spaces as Governance Modes beyond Physical and Political-Administrative Boundaries: \\ examples in Brazil and in Switzerland
}

\begin{abstract}
Espacios Funcionales como Modos de Gobernanza más allá de los Límites Físicos y Político-Administrativos: ejemplos en Brasil y en Suiza
\end{abstract}

\author{
Graziele Muniz Miranda ${ }^{1}$
}

https://orcid.org/0000-0000-0002-5784-9625

\begin{abstract}
RESUMO: A criação de espaços de participação democrática visando a resolução de problemas coletivos é comum atualmente. Representam a rearticulação de lógicas setoriais e a redefinição de perímetros territoriais para a tomada de decisão, indo além de fronteiras físicas ou políticoadministrativas tradicionais. Tal fenômeno, conhecido na literatura inglesa e francesa como soft spaces e espaces fonctionnels, respectivamente, carece de conceituação em português. Esta pesquisa objetivou discutir o conceito de espaço funcional, bem como apresentar exemplos de sua aplicação. Para isso, foi realizada revisão bibliográfica sobre o termo em trabalhos em língua inglesa e francesa. Foi possível apresentar exemplos de espaços funcionais contendo limites difusos no âmbito do planejamento territorial e ambiental em bacias hidrográficas do Brasil e da Suíça.
\end{abstract}

PALAVRAS-CHAVE: Espaço funcional. Participação. Limite.

ABSTRACT: Nowadays, spaces for democratic participation are often created to resolve collective problems. They represent the re-articulation of sectoral logic and the redefinition of territorial perimeters for decision making, going beyond traditional physical or political-administrative boundaries. Such a phenomenon, known in English and French literature as "soft spaces" and "espaces fonctionnels", respectively, needs to be conceptualized in Portuguese. This research aimed to discuss the concept of functional space, as well as to present examples of its application. To this end, a bibliographical review of the term was carried out in English and French papers. It was possible to present examples of functional spaces containing fuzzy boundaries in the territorial and environmental planning area in river basins of Brazil and Switzerland.

KEYWORDS: Soft space. Participation. Boundary.

RESUMEN: La creación de espacios para la participación democrática destinados a resolver problemas colectivos es común hoy en día. Representan la rearticulación de las lógicas sectoriales y la redefinición de los perímetros territoriales para la toma de decisiones, yendo más allá de los límites

\footnotetext{
${ }^{1}$ Doutorado em Geografia pela Université de Lausanne (Suíça). Professora de Geografia no Instituto Federal de Educação, Ciência e Tecnologia de São Paulo. E-mail: gmunizmiranda@gmail.com.
} 
físicos o político-administrativos tradicionales. Tal fenómeno, conocido en la literatura inglesa y francesa como "soft spaces" y "espaces fonctionnelles", respectivamente, carece de conceptuación en portugués. El objetivo de esta investigación fue discutir el concepto de espacio funcional, así como presentar ejemplos de su aplicación. Con este fin, se realizó una revisión bibliográfica del concepto en publicaciones inglesas y francesas. Fue posible presentar ejemplos de espacios funcionales con límites difusos en el ámbito de la planificación territorial y ambiental en cuencas hidrográficas en Brasil y en Suiza.

PALABRAS CLAVE: Espacio funcional. Participación. Limite.

\section{INTRODUÇÃO}

As evoluções nas áreas de tecnologia, informática e transportes tem feito os geógrafos reformularem conceitos tradicionais, como território e região, para incluir as noções de mobilidade e fluidez. Assim, espaços contendo uma base material fixa possuem fronteiras mais ou menos fluidas que mudam invariavelmente pela mudança de função e/ou apropriação simbólica (HAESBAERT, 2014; SOUZA, 1995). Desse modo, ações, sobretudo ligadas à proteção do meio ambiente, à prevenção contra desastres e ao planejamento territorial têm frequentemente limites difusos e móveis.

Porém, políticas públicas possuem, mormente, enfoque setorial (NAHRATH; VARONE; GERBER, 2009). Tal fenômeno é consequência do processo histórico de divisão do trabalho e especialização das atividades produtivas (DURKHEIM, 1967). Assim como no setor industrial, as instituições públicas seguem o formato de divisão por setores. Porém, o fenômeno vai na contramão da realidade socioeconômica e ambiental, difícil de entrar em tal recorte setorial do mundo. Assim sendo, é notória a dificuldade prática em se coordenar instituições e executar políticas públicas que se encontram desvinculadas entre si.

A esse respeito, Nahrath, Varone e Gerber (2009) explicitam que o perímetro dos problemas públicos (sobre os quais são realizadas as políticas públicas) encontram-se em desalinhamento em relação às lógicas setoriais das políticas públicas e, por conseguinte, aos territórios institucionais em que se encontram estabelecidas. Existem, porém, exemplos de criação de espaços de cooperação, como associações e consórcios, por exemplo, que buscam ir ao encontro dos limites reais dos problemas coletivamente construídos; ainda que suas fronteiras não sejam estritamente físicas (como bacias hidrográficas, por exemplo) ou político-administrativas (como limites municipais ou estaduais).

A literatura no idioma português apresenta lacunas sobre sua conceituação, apesar do fenômeno estar presente em discussões, sobretudo àquelas relacionadas a práticas de governança (EMPINOTTI; GONTIJO; OLIVEIRA, 2018; FREY, 2007) e abordagens 
relacionadas à multiterritorialidade atual (HAESBAERT, 2014) proporcionada pelo meio técnico-científico informacional contemporâneo (SANTOS, 1996).

Nas literaturas em inglês e francês, a compreensão da criação de espaços informais voltados ao planejamento urbano e ambiental considerando seus limites difusos é indicado como soft spaces e espace fonctionnel, respectivamente. Desse modo, o presente artigo propõe discutir o conceito de espaço funcional a partir de pesquisa bibliográfica em francês e em inglês, além de ilustrar exemplos de espaços de governança que vão além dos limites físicos e político-administrativos formais: um caso no Brasil e outro, na Suíça.

\section{ESPAÇOS DE GOVERNANÇA QUE NÃO SEGUEM LIMITES FÍsICOS OU POLÍTICO- ADMINISTRATIVOS}

Há três décadas emerge o conceito de governança, promovido pela retração do Estado e pela promoção de políticas neoliberais sob intervenção do Banco Mundial, através do discurso de aumento de eficiência e efetividade governamental (FREY, 2007; GOMIDES; SILVA, 2009). Para além do enfoque das necessidades administrativas, o termo possui potencial emancipador e democrático. É promovido por meio da colaboração de diversos atores envolvidos em prol da melhoria da performance administrativa e da democratização de processos decisórios (FREY, 2007).

Desse modo, a emergência de práticas de governança ocorre ao mesmo tempo em que há um aumento da participação de setores privados na esfera do planejamento. Além disso, tem-se o surgimento de grupos representando a sociedade civil como forma de reivindicar direitos socioeconômicos e ambientais. Assim, desde a década de 1990, têm-se, em âmbito mundial, a multiplicação de instituições e atores que visam participar do processo de planejamento e gestão territorial.

O conceito é utilizado nos dias atuais nas mais diversas áreas, como gestão pública, empresarial, urbana e ambiental, sendo notória sua utilização na literatura nacional e internacional (BALSIGER; MENZEL, 2012; HILL, 2013; OECD, 2015). Trata-se de uma tentativa de atenuar problemas sociais, econômicos e ambientais por meio da participação dos atores locais, sendo uma alternativa à rigidez das tomadas de decisões governamentais unilaterais.

Assim, se por um lado as políticas públicas e as instituições governamentais em geral seguem limites físicos ou político-administrativos fixos, a complexidade da composição dos atores e dos espaços de negociação para resolução de conflitos não segue rigorosamente tais divisões (EMPINOTTI; GONTIJO; OLIVEIRA, 2018; GHIOTTI, 2007; GRAEFE, 2013; GUERRIN; BOULEAU; GRELOT, 2014; MIRANDA, 2017; NAHRATH; VARONE; GERBER, 
2009). Isso mostra-se claramente em várias áreas relacionadas ao planejamento territorial e ambiental.

Ao analisar a reestruturação das relações entre as cidades, Sposito (2016) indica que os sistemas urbanos possuem níveis de integração cada vez maiores em diferentes escalas. Para a autora (2016, p. 127):

O sistema é aberto, não apenas porque as próprias redes o são, mas também porque ele só pode ser compreendido em suas relações em múltiplas escalas. Disso resulta que o esforço em reconhecer seus contornos é bastante difícil e pouco eficaz, porque são mutantes e imponderáveis [...].

Assim como a integração entre as escalas espaciais é progressivamente maior, os conflitos atuais também o são. Segundo Nahrath, Varone e Gerber (2009), o aeroporto de Bruxelas-Nacional é situado na região de Flandres. Porém, o maior fluxo de voos está na região de Bruxelas-capital. Dessa forma, se os efeitos positivos em termos de emprego, recebimento de impostos e desenvolvimento regional localizam-se em Flandres, os efeitos negativos como o aumento do tráfego aéreo, risco de acidentes e poluição sonora permanecem em Bruxelas. Os autores salientam que as instituições formais existentes são limitadas quanto à conciliação de tais impasses. Por isso, enfocam a necessidade de criação de políticas públicas que vão além dos limites rígidos entre fronteiras políticoadministrativas como sendo imprescindível para a resolução de tais problemas coletivos.

Por sua vez, quando se discute a gestão de recursos hídricos no Brasil, a unidade territorial para planejamento e gestão é a bacia hidrográfica, por ser considerada como fronteira natural (BLOMQUIST; SCHLAGER, 2005). Entretanto, na prática, a escolha dos limites da bacia não é simples e muitas vezes não considera apenas aspectos naturais, mas sobretudo questões políticas e socioeconômicas. Sua concepção engendra problemas práticos ligados a (1) questão do perímetro da bacia, (2) questão de tamanho, (3) questão de transferências de água e (4) questão política (GRAEFE, 2013; MIRANDA; REYNARD, 2020).

A escolha do perímetro da bacia pode trazer dificuldades. O próprio recorte do estado de São Paulo em Unidades de Gerenciamento de Recursos Hídricos (UGRHI) não seguiu limites rígidos, pois a bacia hidrográfica do rio Tietê foi dividida em seis unidades territoriais segundo os usos de água preponderantes e questões socioambientais próprias, ou seja, sua escolha justifica-se por questões estratégicas e não puramente hidrológicas. Outra questão é o fato da transferência de água entre bacias diferentes, como é o caso do abastecimento de água para a região metropolitana de São Paulo, não seguir os limites de uma bacia hidrográfica e sua gestão gerar conflitos sobretudo durante épocas de crise hídrica (EMPINOTTI; BUDDS; AVERSA, 2019; MILANO et al., 2018). Dessa forma, a escala em 
que a governança da água acontece transcende os limites hidrológicos das bacias hidrográficas (ARRETCHE, 2012; EMPINOTTI; GONTIJO; OLIVEIRA, 2018).

\section{CONCEITUAÇÃO DE ESPAÇOS FUNCIONAIS}

Desde a última década, territórios de governança que vão além de limites físicos e político-administrativos são tratados por bibliografia inglesa e francesa. O termo inglês soft space trata-se de um tipo particular de território, resultado de uma estratégia para representar uma área geográfica de modo inovador que vai além das fronteiras políticoadministrativas e de divisões territoriais internas, especialmente onde existe significativa resistência para abordagens de governança intersetorial e múltiplos atores (ALLMENDINGER; HAUGHTON, 2009; ALLMENDINGER et al., 2015).

Haughton e Allmendinger (2007) iniciaram as discussões em torno do conceito de espaço funcional no contexto da governança com foco no planejamento territorial. O termo vem sendo analisado sobretudo em estudos de caso europeus. Para Thomas e Littlewood (2010), o conceito refere-se a arranjos informais de governança espacial. Desse modo, soft spaces opõem-se à noção de hard spaces (aqui traduzidos como "espaços rígidos"), estes relacionados às administrações formais. Assim, soft spaces tentam superar os padrões preexistentes, normalmente lentos e burocráticos, que não refletem as geografias reais dos problemas e oportunidades. Além disso, tais espaços refletem novas formas de colaboração buscando aumentar a eficiência do processo de planejamento através das fronteiras do conflito em questão.

Através de diferentes experiências europeias de soft spaces, Allmendinger et al. (2015) indicam que governanças a partir de hard e soft spaces trabalham em conjunto. Isso significa que a ideia não é trocar hard spaces por soft spaces, mas criar complementaridade e oportunidade para o andamento de atividades que possuem limites difusos, e não somente pensar na tradicional escala de governo sub-regional ou local. Neste sentido, o planejamento territorial sob o enfoque de soft spaces não obrigatoriamente significa apenas soft formas de planejamento. Pode e recomenda-se que o planejamento seja desenvolvido através de estratégias formais e informais.

Para Bialasiewicz, Elden e Painter (2005), a política territorial europeia reproduz um modo de territorialidade compreendida como significativamente diversa da rigidez da territorialidade dos Estados-nação, pois não é baseada em controle político unilateral, mas em normas e objetivos políticos compartilhados. Assim, programas como o Interreg Europe (INTERREG, 2019), visando a cooperação entre autoridades públicas locais e sub-regionais na União Europeia, podem ser exemplos de soft spaces. 
Adam e Green (2016) utilizam o termo ao apresentarem a iniciativa City Strategy, na Grã-Bretanha. Tal iniciativa enfatiza a importância do trabalho da parceria local, onde vários atores fazem acordos em um espaço flexível para alcançar metas comuns. Telle (2017) analisa a importância da cooperação em euroregiões (áreas englobando fronteiras entre países europeus) como forma de superar a periferização de regiões fronteiriças em relação a aspectos econômicos e sociais. O autor (Id.) indica que acordos mais flexíveis visando a prestação de serviços nessas áreas podem promover o fortalecimento da coordenação transfronteiriça horizontal. Haxhija (2018) analisa igualmente a existência de diversas redes informais em área de fronteira entre a Holanda e a Alemanha. Para o autor (Id.), existem dificuldades por parte dos atores governamentais e não-governamentais ao tentarem cooperar devido às diferenças culturais e à estrutura institucional. Possuindo abordagem similar, a literatura francófona traz o conceito de espace fonctionnel. Para Nahrath, Varone e Gerber (2009, p. 6, tradução própria), trata-se de:

[...] uma área onde se constrói um problema coletivo a ser resolvido, reconhecido como tal (ou seja, construído através de lutas políticas) por diversos atores privados e públicos. Representa assim o perímetro social ou geográfico que é aceito como pertinente para a gestão do dito problema. Funciona igualmente como o espaço político legítimo e adequado, em termos de eficácia presumida, para arbitrar as rivalidades entre os produtores e os destinatários dos bens e serviços em questão.

Assim, o termo apresenta uma ferramenta analítica que permite considerar fenômenos de formatação alternativa da ação pública. Tanto na literatura inglesa quanto na francesa, tais conceitos indicam uma forma de redefinir os perímetros territoriais e rearticular as lógicas setoriais objetivando repensar as fronteiras dos espaços de governança. Formados estrategicamente sobretudo a partir de lideranças públicas locais, podem existir por tempo determinado ou não e visam resolver um problema criado coletivamente considerando o perímetro do fenômeno em si a partir de uma lógica intersetorial.

A figura 1 apresenta a interdependência entre os espaços formais, identificados como "espaços rígidos", e os espaços funcionais. A divisão em duas partes identifica claramente os elementos que compõem cada um dos espaços. Os espaços rígidos, concebidos por meio de hierarquias e obrigações legais - como implementação de políticas e planos -, são frequentemente caracterizados por complexidade e atrasos. Espaços funcionais são áreas de maior fluidez entre os processos formais por meio do predomínio de negociações e maior flexibilidade.

Os espaços funcionais são, em última análise, reflexo da maior fluidez do ponto de vista econômico, político e cultural vivenciado atualmente. Aproxima-se, em certa medida, aos "territórios-rede" e aos "aglomerados" discutidos por Haesbaert (2014). O autor identifica 
a integração, a coexistência e a influência mútua entre os chamados "territórios-zona", territórios-rede e aglomerados. Para o mesmo, território-zona é associado às leituras mais tradicionais de território, possuindo geometria euclidiana e entendido como homogêneo e dissociado da ideia de movimento. Por outro lado, territórios-rede são descontínuos e produzidos por movimentos articulados, formados pela lógica reticular de controle de fluxos e polos de conexão. Não dissociado dos anteriores, um aglomerado é composto por espaços fluidos em que não apenas os limites não são nítidos, mas os objetos produzidos não são bem distinguíveis. Além disso, os comportamentos dos aglomerados são imprevisíveis. O autor (2014) analisa o último termo sobretudo para discutir sobre as massas de despossuídos ao abordar os "aglomerados de exclusão", sem relacioná-los direta e profundamente ao processo de planejamento urbano e ambiental.

Figura 1 - Relação entre espaços "rígidos" e "funcionais"

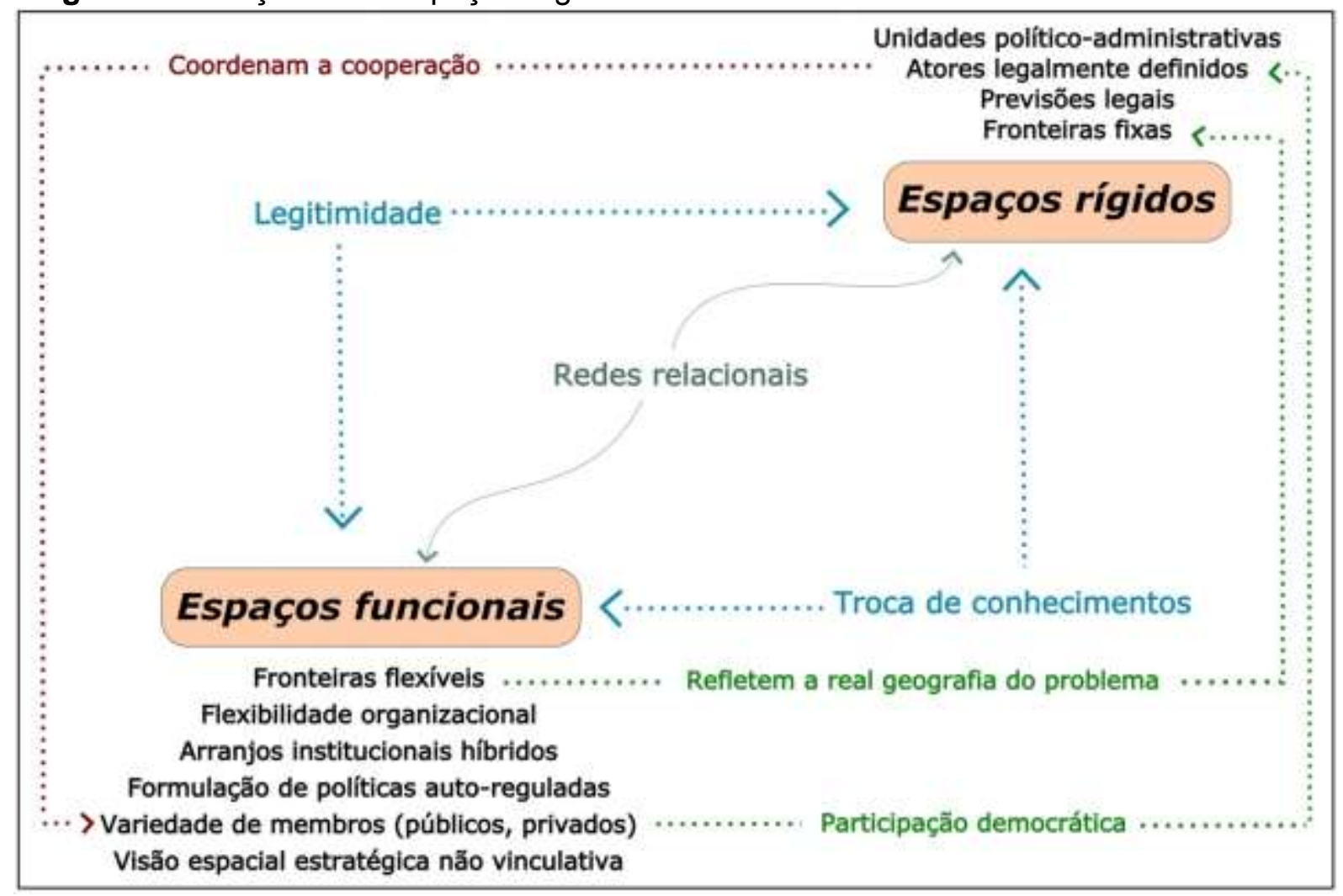

Fonte: adaptado de Haxhija (2018).

Espaço funcional é similar ao conceito de território-rede pela sua descontinuidade e lógica reticular. Entretanto, territórios-rede estão ligados sobretudo a questões de mobilidade e tecnologia; enquanto espaços funcionais não necessariamente são móveis, mas envolvem determinado fenômeno ou problema que não segue, porém, limites tradicionais (como político-administrativos ou hidrológicos). Ao mesmo tempo, espaço funcional aproxima-se de aglomerado por ser um espaço cujos limites são difusos. Porém, 
difere deste último porque os atores e os objetos produzidos são visíveis e podem, em alguns casos, ser previsíveis, como evidenciado com a criação de arranjos alternativos de planejamento.

\section{EXEMPLO DE ESPAÇO FUNCIONAL NA BACIA HIDROGRÁFICA DOS RIOS PIRACICABA, CAPIVARI E JUNDIAÍ - SP}

No Brasil, o exemplo do Consórcio Intermunicipal das Bacias Hidrográficas dos Rios Piracicaba e Capivari (2018) (e posterior entrada de Jundiaí) pode ser considerado como um espaço funcional, pois trata-se de um arranjo de governança alternativa para resolução de problemas locais. O chamado Consórcio PCJ foi criado no ano de 1989, antes mesmo da primeira lei estadual de recursos hídricos (paulista, promulgada em 1991) e da lei federal (promulgada em 1997); por meio da adesão de doze municípios objetivando o aumento do tratamento de esgoto e da qualidade dos rios na região. Sua criação visou igualmente ser uma força política frente aos governos estaduais e federal.

Trata-se de uma associação de direito privado sem fins lucrativos, em que os membros são convidados a participar de forma voluntária por meio do pagamento de uma contribuição para a execução de projetos de revitalização e proteção de mananciais e campanhas de conscientização ambiental.

Os trabalhos do Consórcio PCJ continuaram mesmo após a formação do comitê de bacias hidrográficas Piracicaba, Capivari e Jundiaí (PCJ), órgão consultivo e deliberativo sobre a gestão de águas na região previsto por lei estadual e criado em 1993. Na realidade, ambos os organismos cooperaram diversas vezes, sobretudo entre 2005 e 2011, quando o consórcio foi escolhido para realizar as funções de agência de bacia (secretaria executiva do comitê) e como responsável pela aplicação do sistema de cobrança nas bacias PCJ (MIRANDA, 2017). Em 2020, além dos 40 municípios membros (quase $70 \%$ do total dos munícipios com sede nas bacias) (Figura 2), 25 empresas participavam da instituição.

Ainda que boa parte dos municípios membros participe de ambas as instituições, a formatação do consórcio é alternativa em relação ao seu território e ação pública. Sua criação não se originou de obrigações legais e sua formação não segue rigorosamente limites hidrológicos nem político-administrativos (presença de empresas). Além disso, sua composição varia com o passar do tempo, de acordo com a adesão voluntária de seus membros, possuindo assim fronteiras flexíveis. Ademais, trata-se de uma entidade executora de projetos técnica e financeiramente independente. Nesse sentido, o Consórcio PCJ possui forte autonomia em relação aos trabalhos prestados. Dessa forma, trata-se de um espaço criado para a resolução de problemas coletivos sem possuir limites físicos ou político-administrativos rígidos, ou seja, um espaço funcional. 
Figura 2 - Localização dos municípios membros do Consórcio Intermunicipal PCJ em 2020

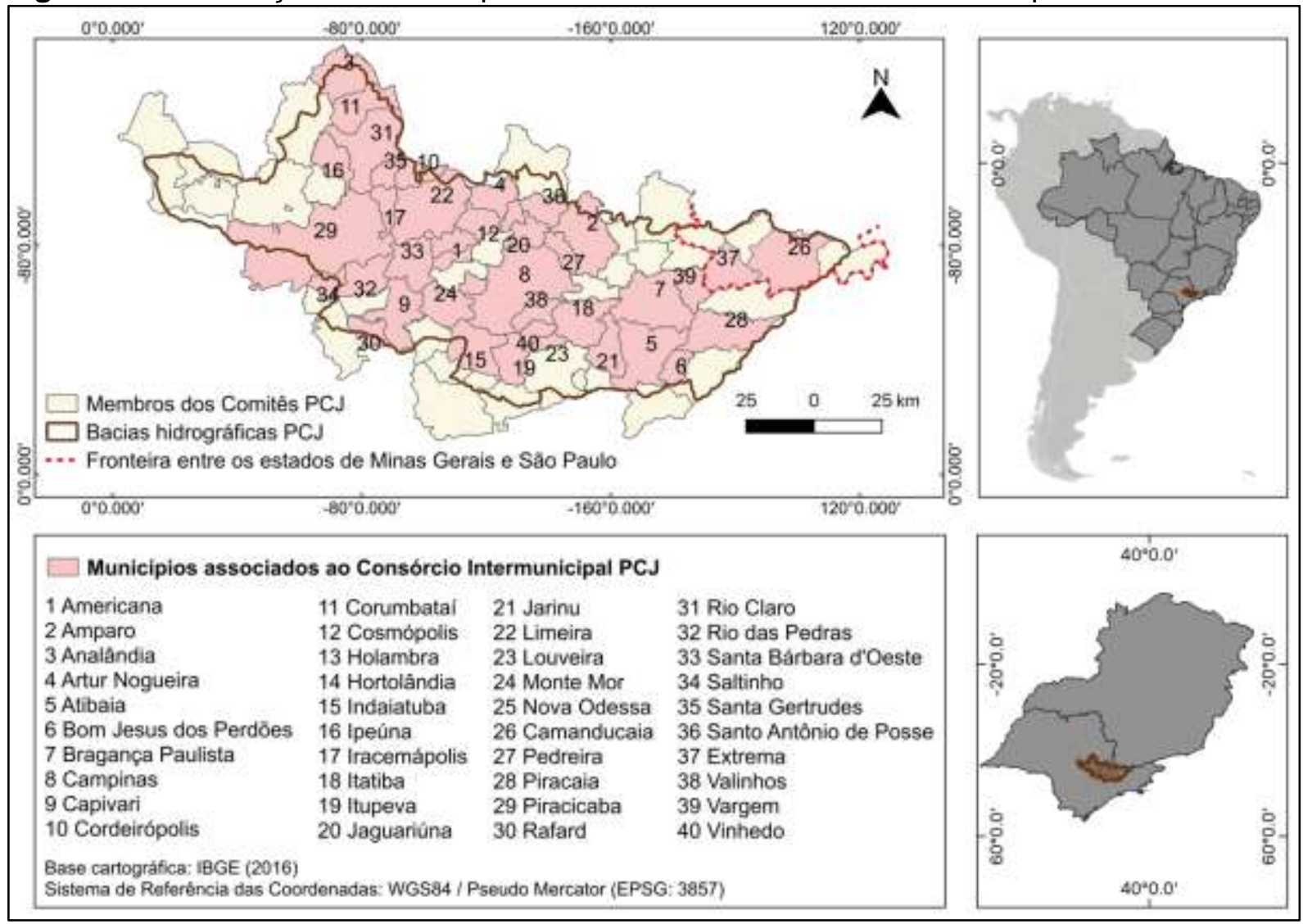

Fonte: elaborado pela autora.

\section{EXEMPLO DE ESPAÇO FUNCIONAL NA BACIA HIDROGRÁFICA MÈBRE-SORGE, VAUD, SUÍÇA}

Para facilitar a compreensão de um exemplo de gestão de águas em uma pequena bacia hidrográfica na Suíça, convém primeiramente esclarecer de forma resumida o tipo de federalismo do país. Diferentemente do Brasil (ARRETCHE, 2012; EMPINOTTI; GONTIJO; OLIVEIRA, 2018), a Suíça é um dos países federais mais descentralizados e participativos do mundo. A forte autonomia cantonal resulta da origem do federalismo suíço (reagrupamento de Estados soberanos) e da crença que o poder local será sempre melhor que a tomada de decisão distante dos cidadãos (DARDANELLI, 2010). Dessa forma, a maioria das áreas de competência federal são decididas e executadas na prática pelos cantões. O governo federal possui papel fiscalizador e estabelece normas bastante gerais.

A participação é garantida por instrumentos previstos na Constituição Federal, como referendo obrigatório, referendo facultativo e iniciativa popular, encontrados tanto no nível federal, quanto cantonal (como estados, no Brasil) e comunal (como municípios, no Brasil). A respeito do referendo obrigatório, um ato do parlamento (como a alteração da 
Constituição, por exemplo) só entra em vigor após ter sido aceito por escrutínio popular. Quanto ao referendo facultativo, o povo decide através do voto pela alteração de leis, decretos e tratados internacionais desde que 50 mil eleitores ou oito cantões o peçam. Em relação à iniciativa popular, pode haver revisão da Constituição Federal caso ao menos 100 mil suíços assim o queiram. No âmbito cantonal e comunal, tal instrumento diz respeito às mudanças constitucionais e legislativas.

$\mathrm{Na}$ área de gestão de recursos hídricos, o país conta com exemplos locais explicitamente heterogêneos e é marcado pela falta de interesse pela criação de novas instituições, pois as comunas temem perder sua autonomia política, já que são normalmente elas (autonomia comunal variável de acordo com o cantão) as responsáveis pela execução da gestão de águas (MIRANDA; REYNARD, 2020). Assim, ao invés de um modelo único de gestão nacional, o nível federal encoraja a coordenação de múltiplos atores interessados em determinado projeto. Trabalha-se, assim, pela resolução de problemas considerados como prioritários, evidenciando o perfil eminentemente pragmático do país.

Para superar os desafios da fragmentação setorial sem a necessidade de criar-se novas instituições, modos de colaboração informais tendo fronteiras flexíveis são formados com o intuito de coordenar usos considerados prioritários durante a execução de determinados projetos (BUCHS, 2018; SCHEUCHZEL et al., 2012; SCHMID et al., 2014). Tais espaços são normalmente criados temporariamente e possuem características pragmáticas. Desse modo, o governo federal considera que a consideração da bacia hidrográfica não deve ser uma regra (COMITE DE DIRECTION DU PNR 61, 2015). Incentiva antes a criação de espaço informal com limites flexíveis em âmbito local. Tais espaços podem ser compostos por representantes de dois ou mais usos da água, de acordo com as necessidades locais.

Um exemplo refere-se à criação de instituições no cantão de Vaud, situado a cerca de 60 quilômetros de distância da cidade de Genebra. A associação intermunicipal Entente intercomunal Mèbre-Sorge foi criada em 1967 por cinco municípios (Chavannes-prèsRenens, Ecublens, Renens, Saint-Sulpice e Crissier, que a dirige) para dividir custos com a construção e o gerenciamento da rede de esgotos. Tal rede segue em direção à estação de tratamento de esgotos de Vidy, em Lausanne. Esta estação é responsável por tratar efluentes de 13 municípios da região, sob o gerenciamento da Comissão Intermunicipal da Estação de Tratamento de Vidy (CISTEP). Qualquer decisão relativa ao financiamento, planejamento do sistema ou entrada de uma nova comuna em ambas as entidades é decidida pelos membros. Tais entidades relacionam-se entre si sem seguir limites hidrológicos nem administrativos fixos, pois a entrada e saída dos municípios são variáveis (Figura 3). 
Figura 3: Localização dos municípios membros da Associação Intermunicipal MèbreSorge (à esquerda) e localização dos municípios membros da Comissão Intermunicipal da Estação de Tratamento de Efluentes de Vidy (CISTEP) (à direita) em 2016

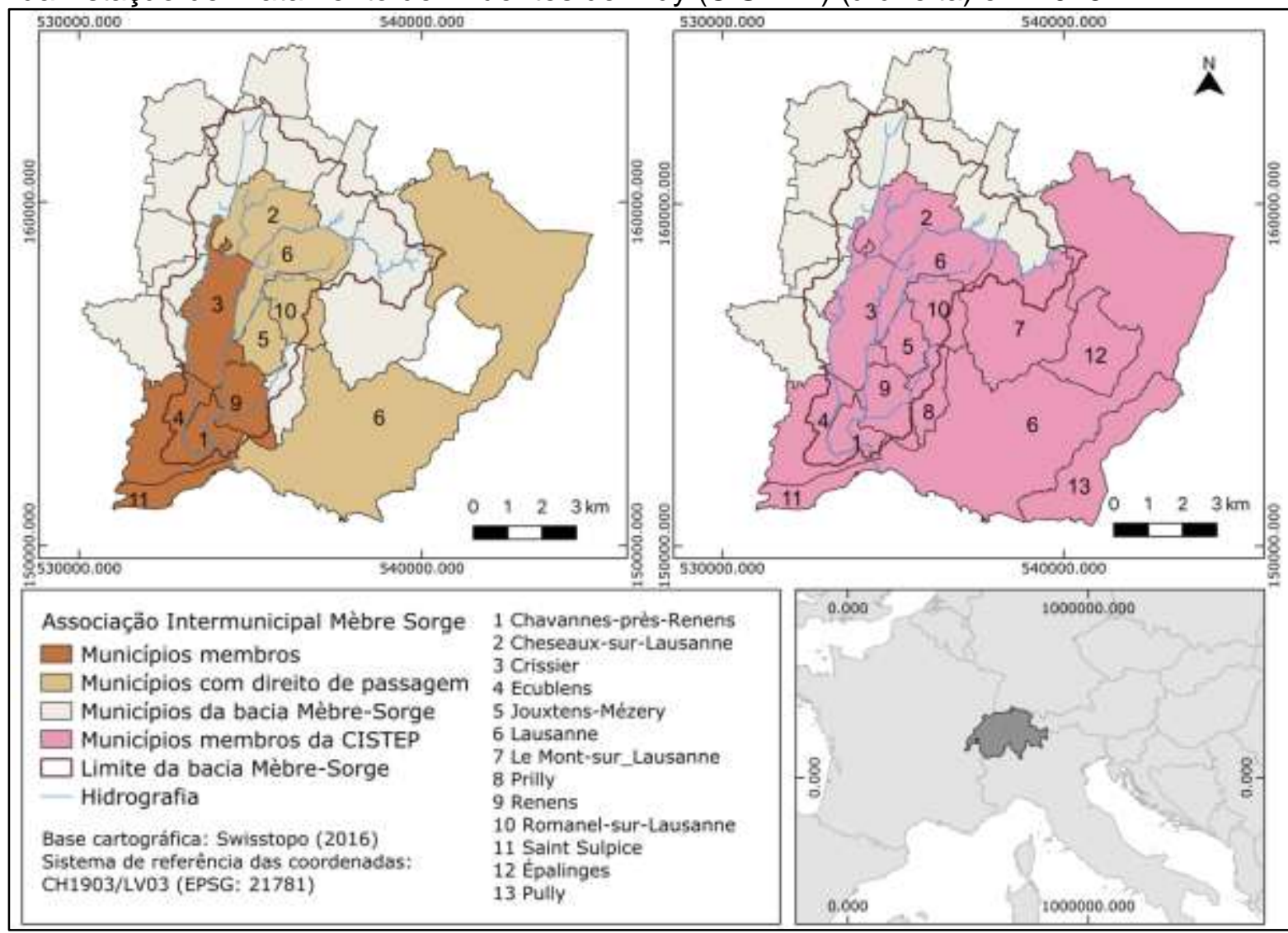

Fonte: elaborado pela autora.

O principal motivo de sua existência é o fato de os municípios serem muito pequenos e por isso ser vantajoso dividir-se os custos com o tratamento de efluentes ao invés de cada município ter sua estrutura própria.

Os governantes e membros da sociedade civil organizada em âmbito federal, cantonal e local não têm interesse em criar comitês de bacia pelos moldes franceses ou brasileiros porque acreditam que isso dificultaria o planejamento e a gestão das águas e deixaria o processo mais lento (MIRANDA, 2017; MIRANDA; REYNARD, 2020; UTZ; CLIVAZ; REYNARD, 2017). Eles preferem trabalhar a partir de prioridades a serem resolvidas, ainda que o processo não leve necessariamente em conta os múltiplos usos de água na bacia. Por isso, é comum a criação de grupos de trabalho envolvendo diferentes atores para resolvê-lo de acordo com os usos impactados, sem seguir limites territoriais rígidos.

\section{CONSIDERAÇÕES FINAIS}

Espaços de governança com fronteiras alternativas aos tradicionais limites físicos e político-administrativos são conceituados em literatura inglesa e francesa como soft spaces 
e espaces fonctionnels, respectivamente. Tais espaços buscam ir ao encontro de soluções conjuntas referentes a conflitos territoriais e ambientais por possuírem fronteiras flexíveis, assim como tais conflitos. Representam assim uma tentativa de introduzir formas inovadoras de abordagem dos problemas.

Porém, a literatura em português apresenta uma lacuna na conceituação de tal fenômeno territorial. Além de conceituar o termo "espaço funcional", este artigo apresentou exemplos de sua aplicação no âmbito da gestão de recursos hídricos por meio de casos diferenciados: a existência de um consórcio intermunicipal no interior do Estado de São Paulo e entidades intermunicipais no Cantão de Vaud, Suíça. Tais exemplos ultrapassam os limites hidrológicos e municipais. Além disso, todos refletem uma nova forma de colaboração para resolver problemas coletivos que são mais coerentes com o perímetro do problema em relação às fronteiras convencionais.

A discussão acerca de sua aplicação no Brasil pode trazer diferentes contribuições. llustra-se aqui algumas possibilidades: compreender como ocorre a inter-relação e a cooperação entre os espaços rígidos e informais; entender como os espaços funcionais influenciam o planejamento territorial; analisar de que forma o neoliberalismo influencia a criação de novos espaços funcionais.

\section{REFERÊNCIAS}

ADAM, Duncan; GREEN, Anne E. Soft spaces and soft outcomes: experiences from city strategy on local partnership working and measures of success. Environment and Planning A: Economy and Space, London, GB, v. 48, n. 8, p. 1514-1531, 2016.

ALLMENDINGER, Phil; HAUGHTON, Graham. Soft spaces, fuzzy boundaries and metagovernance: the new spatial planning in the Thames Gateway. Environment \& Planning, Thousand Oaks, v. 41, n. 3, p. 617-633, 2009. Disponível em: https://doi.org/10.1068/a40208. Acesso em: 10 jun. 2020.

ALLMENDINGER, Phil et al. Soft spaces in Europe: re-negotiating governance, boundaries and borders. New York: Routledge, 2015.

ARRETCHE, Marta. Democracia, federalismo e centralização no Brasil. Rio de Janeiro: FGV/Fiocruz, 2012.

BALSIGER, Jörg; MENZEL, Susanne. Auf dem Weg zu einer integrierteren Wasserpolitik in der Schweiz: Kantonale Koordinationsformen und - mechanismen. Teilbericht zum Arbeitspaket 2.1 des Projekts, 2012. Disponível em: https://wa21.ch/wpcontent/uploads/2017/09/Schlussversion_IWAGO_WP2_1.pdf. Acesso em: 10 jun. 2020.

BIALASIEWICZ, Luiza; ELDEN, Stuart; PAINTER, Joe. The Constitution of EU Territory. Comparative European Politics, Claverton Down, v. 3, p. 333-363, 2005.

BLOMQUIST, William; SCHLAGER, Edella. Political pitfalls of integrated watershed management. Society \& Natural Resources, London, v. 18, p. 101-117, 2005.

BUCHS, Arnaud. Integrated water resources management as a compromise: renewing the water act in the canton of Fribourg, Switzerland. In: BRETHAUD, Christian; SCHWEIZER, 
Rémi (Orgs.) A critical approach to international water management trends: policy and practice. London: Palgrave Macmillan, 2018. p. 45-69.

COMITE DE DIRECTION DU PNR 61. Gestion durable de l'eau en Suisse: le PNR 61 montre les voies à suivre pour l'avenir. Synthèse globale dans le cadre du Programme national de recherche "Gestion durable de l'eau". Berne: Comite de Direction du PNR 61, 2015.

CONSÓRCIO INTERMUNICIPAL DAS BACIAS DOS RIOS PIRACICABA, CAPIVARI E JUNDIAÍ. O Consórcio Intermunicipal PCJ. Americana, SP: CONSÓRCIO PCJ, 2018. Disponível em: https://agua.org.br/. Acesso em: 30 abr. 2019.

DARDANELLI, Paolo. Federal democracy in Switzerland. London: Routledge, 2010. (Routledge Series in Federal Studies).

DURKHEIM, Émile. De la division du travail social. Paris: Les Presses universitaires de France, 1967. Disponível em:

http://classiques.uqac.ca/classiques/Durkheim_emile/division_du_travail/division_travail_1.p df. Acesso em: 29 abr. 2019.

EMPINOTTI, Vanessa Lucena; BUDDS, Jessica; AVERSA, Marcelo. Governance and water security: the role of the water institutional framework in the 2013-15 water crisis in São Paulo, Brazil. Geoforum, Amsterdam, v. 98, p. 46-54, 2019.

EMPINOTTI, Vanessa Lucena.; GONTIJO, Wilde Cardoso; OLIVEIRA; Vanessa Elias de. Federalism, water, and (de)centralization in Brazil: the case of the São Francisco River water diversion. Regional Environmental Change, New York, US, v. 18, n. 6, p. 1655-1666, 2018.

FREY, Klaus. Governança urbana e participação pública. RAC: Revista de Administração Contemporânea, Maringá, PR, v. 1, n. 1, p. 136-150, 2007. versão online. Disponível em: http://www.anpad.org.br/rac-e. Acesso em: 30 abr. 2019.

GHIOTTI Stéphane. Les territoires de l'eau: gestion et développement en France. Paris: Editions du CNRS, 2007.

GOMIDES, José Eduardo; SILVA, Andréa Candida. O surgimento da expressão "governance", governança e governança ambiental: um resgate teórico. São Paulo: Instituto de Pesquisas Aplicadas e Desenvolvimento Educacional (IPADE), 2009.

GRAEFE, Olivier. The river basin as a territorial water management unit: towards postpolitical water management. In: FASSETA, Gilles Arnaud; MASSON, Eric; REYNARD, Emmanuel. (orgs.). European continental hydrosystems under changing water policy. München: Pfeil, 2013. p. 11-16.

GUERRIN, Joana; BOULEAU, Gabrielle; GRELOT, Frédéric. Functional fit versus politics of scale in the governance of floodplain retention capacity. Journal of Hydrology, Amsterdam, NL, v. 519, p. 2405-2414, 2014.

HAESBAERT, Rogério. O mito da desterritorialização: do "fim dos territórios" à multiterritorialidade. Rio de Janeiro: Bertrand Brasil, 2014.

HAUGHTON, Graham; ALLMENDINGER, Phil. 'Soft spaces' in planning. Town and Country Planning, London, GB, v. 76, p. 306-308, 2007.

HAXHIJA, Sindi. An institutional and cultural perspective on 'soft' spaces of cooperation: Findings from a transboundary Dutch-German cooperation network. 2018. Dissertação (Mestrado em Planejamento Territorial e Desenvolvimento Regional) - Radboud University, Nimega, 2018.

HILL, Margot. Climate change and water governance adaptive capacity in Chile and Switzerland. Geneva: Springer, 2013. 
INTERREG EUROPE. What is interreg Europe? 2019. Disponível em: https://www.interregeurope.eu/about-us/what-is-interreg-europe/. Acesso em 30 abr. 2019.

MILANO, Marianne et al. Water supply basins of São Paulo Metropolitan Region: hydroclimatic characteristics of the 2013-2015 water crisis. Water, Basel, v. 10, n. 11, p. 1-19, 2018.

MIRANDA, Graziele Muniz. Gestion intégrée des ressources eau dans les pays fédéraux: les cas suisse et brésilien. 2017. Tese (Doutorado em Geografia). (Géovisions n46). Université de Lausanne, Lausanne, 2017.

MIRANDA, Graziele Muniz; REYNARD, Emmanuel. Integrated water resources management in Federations: the examples of Brazil and Switzerland. Water, Basel, v. 12, n. 1914, 2020. Disponível em: https://doi.org/10.3390/w12071914. Acesso em: 20 ago. 2020.

NAHRATH, Stéphane; VARONE, Frédéric; GERBER, Jean-David. Les espaces fonctionnels: nouveau référentiel de la gestion durable des ressources? VertigO: La Revue Électronique en Sciences de L'environnement, Montréal, v. 9, n. 1, p. 1-14, 2009. Disponível em: https://vertigo.revues.org/8510. Acesso em: 28 abr. 2016.

OECD. Governança dos recursos hídricos no Brasil. Paris: OECD Publishing, 2015. Disponível em:

http://www.inea.rj.gov.br/cs/groups/public/documents/document/zwew/mtew/ e disp/inea0110761.pdf. Acesso em: 28 abr. 2016.

SANTOS, Milton. A natureza do espaço. São Paulo: Hucitec, 1996.

SCHEUCHZER, Patrick et al. IWAGO: Integrated Water Governance With Adaptive Capacity in Switzerland. Zürich, Dübendorf: Eidgenössische Technische Hochschule: Eawag, 2012.

SCHMID, Franziska et al. Gouvernance durable de l'eau: enjeux et voies pour l'avenir. Bern, Suíça: Fonds National Suisse De La Recherche scienfique, 2014. PNR61- syntèse thématique 4.

SOUZA, Marcelo José Lopes de. O território: sobre espaço, poder, autonomia e desenvolvimento. In: CASTRO, Iná Elias de; GOMES, Paulo Cesar da Costa; CORRÊA, Roberto Lobato (eds.). Geografia: conceitos e temas. Rio de Janeiro: Bertrand Brasil, 1995. p. 77-116.

SPOSITO, Maria Encarnação Beltrão. A produção do espaço urbano: escalas, diferenças e desigualdades socioespaciais. In: CARLOS, Ana Fani Alessandri; SOUZA, Marcelo Lopes de; SPOSITO, Maria Encarnação Beltrão (orgs.). A produção do espaço urbano: agentes e processos, escalas e desafios. São Paulo: Contexto, 2016. p. 123-146.

TELLE, Stefan. Euroregions as soft spaces: between consolidation and transformation. European Spatial Research and Policy, Łódź, Polônia, v. 24, n. 2, p. 93-110, 2017.

THOMAS, Kevin; LITTLEWOOD, Steve. From green belts to green infrastructure? The evolution of a new concept in the emerging soft governance of spatial strategies. Planning, Practice and Research, London, v. 25, n. 2, p. 203-222, 2010.

TORRES, Nilton Ricoy. Planejamento numa sociedade em rede: práticas de planejamento colaborativo no Brasil. Cadernos Metrópole, São Paulo, SP, v. 11, n. 22, p. 571-591, 2009.

UTZ, Stephan; CLIVAZ, Mélanie; REYNARD, Emmanuel. Processus participatifs et projets d'aménagement des cours d'eau. Analyse de l'implication des acteurs dans la planification du projet de 3ème correction du Rhône suisse entre 2000 et 2015. Géocarrefour, Lyon, França, v. 91, n. 4, p. 1-20, 2017.

Recebido: maio de 2020. Aceito: agosto de 2020. 